Received 30 April 2019; accepted 15 July 2019.

Available online 1 October 2019

\title{
A Platform for Design \\ Pattern Language as a Tool for Enhancing Non-Motorized Paths
}

\author{
Yasmeen Elsemary \\ Assistant Professor, Arab Academy for Science, Technology and Maritime Transport, Smart \\ Village Campus \\ ysemary@gmail.com, ysemary@aast.edu
}

\begin{abstract}
Pedestrian and bicycle paths considered as Non-Motorized paths are quite responsible for raising the social quality of life for cities' residents and visitors as well, aiming at achieving the highest level of well-being, thus, directly affect the users' level of satisfaction. Based on physical standards represented in environmental and economic attributes, as well as moral standards represented in social, cultural and psychological attributes, the research aims at discussing the role of Non-Motorized paths in raising the cities' social quality of life.

The research methodology includes a comprehensive literature review, analytical part and a practical part. The hypothesis of non-motorized paths act as a catalyst to the social quality of life attributes is to be discussed extensively in the literature review, while the analytical part aims at studying the leading international models in social quality of life deducing the full detailed attributes that contribute to measuring and upgrading the quality of non-motorized traffic paths. At the end the practical part includes proposing a platform for design based on selected design theories, targeting recruiting these theories in a functional way, aims at assessing and upgrading local models in Greater Cairo, with the help of the attributes derived from the previous analytical part. The local models in Greater Cairo selected to be in Cairo City Center; Al Shawarby Street, moreover surveys are the Tools of investigation and assessment within thorough observations to the case.

The research findings demonstrate the great ability of non-motorized paths in providing safety attributes, and entertainment factors, meeting different cultural and social needs for the users, enhancing as well the aesthetic aspect and the visual image of the city, thus the physical and moral standards are well supported, and the social quality of life is well enhanced.
\end{abstract}

KEYWORDS: Non-Motorized paths- Pattern Language- Cairo City Center- Social Quality of life.

\section{INTRODUCTION}

Streets are the fundamental public space in every city, the main stream of social exchange. Yet today, more and more streets are simply choked with car traffic lacking a space for pedestrians and bicyclists. A simple principle then evolved: if you plan cities for cars and traffic, you get cars and traffic. If you plan for people and 
places, you get people and places; it is the aim of starting with the decision to design streets as comfortable and safe places for people on foot, not people in cars. Streets that are planned for people, meaning they are not completely auto centric, they add to the social cohesion of communities by ensuring human interaction, and providing safe public spaces that promote cultural expression. And because a city's best public spaces are multi-use destinations, holding many design features that are essential to users, they are places that attract people of all ages and income groups, men and women alike, and they are acting as a common ground for citizens, thus communities everywhere can decide what it is that makes their public spaces a common destination. Is it an amenity? Is it a performance space? Is it a place for youth? Is it a market for local products? Is it a place for Artifacts? Or is it a safe and secured place? Most probably the answer is more than one of these, yet the mix is up to the people who will definitely use the place. Accordingly, the target was integrating the citizens in this process for that community has a holistic vision and should lead the professionals in implementing that vision and acting as facilitators and resources. Thus the key is to improve communication between the people and local government.

Consequently, since this subject had been discussed before in several researches, then on an attempt to deal with the subject within a different application, This paper introduces solving design problems in the local non-motorized paths based on people understanding of their social needs and requirements, this would be done through applying 'pattern language' theory; a theory set by Christopher Alexander as an attempt to enhance social quality of life through non-motorized paths, the case study to be investigated and tested is Al Shawarby Street, Down Town.

\section{RESEARCH PROBLEM}

Activating the theories of Design is not necessarily implemented in every design process, thus leads to lacking tangible platforms for applying theories of design in different settings.

\section{RESARCH AIM}

The research attempts in activating local non-motorized paths to fulfill man needs encountering functional, environmental, aesthetical and contextual aspects with the help of Design theories.

\section{RESEARCH HYPOTHESIS}

If Non-Motorized paths considered to be as catalyst to the social quality of life attributes, as well as activating the Non-Motorized paths by implementing theories of design with special consideration to all aspects of function, environment, and context.... etc. then this would be more effective and would provide the users with their needs and requirements, moreover would support the social quality of life.

\section{METHODOLOGY}

The research methodology includes a comprehensive literature review, analytical part and a practical part. Social quality of life attributes to be discussed extensively in the literature review within the definitions of non-motorized paths, while the 
analytical part aims at investigating the relationship between the quality of nonmotorized paths and the social quality of life for users in the city by focusing on one of design theories 'pattern language' analyzing the different languages leading to solving design problems in the non-motorized paths, within the help of leading international models deducing the full detailed attributes that contribute to measuring and upgrading the quality and efficiency of non-motorized traffic paths, Las Ramblas street in Barcelona is taken as an analytical case study. At the end the practical part proposes a platform for design based on 'pattern language' theory by Christopher Alexander, targeting recruiting this theory in a functional way, aims at upgrading local non-motorized paths in Greater Cairo, with the help of the attributes derived from the previous analytical part. Al Shawarby Street-Downtown is the case study to be investigated; surveys are the Tools of investigation and assessment within thorough observations to the case. Moreover, as an attempt to recruiting the theory, a matrix is done consisting of the volunteers' survey responses and needs with the significance from the pattern languages and an illustration through a photo or a sketch by the author, then an application to the pattern 'shopping street' as stated in Christopher Alexander book, in which tying all the patterns together to solve the design problems in the non-motorized paths. Research methodology is shown in figure (1).

Figure (1) Research Methodology diagram

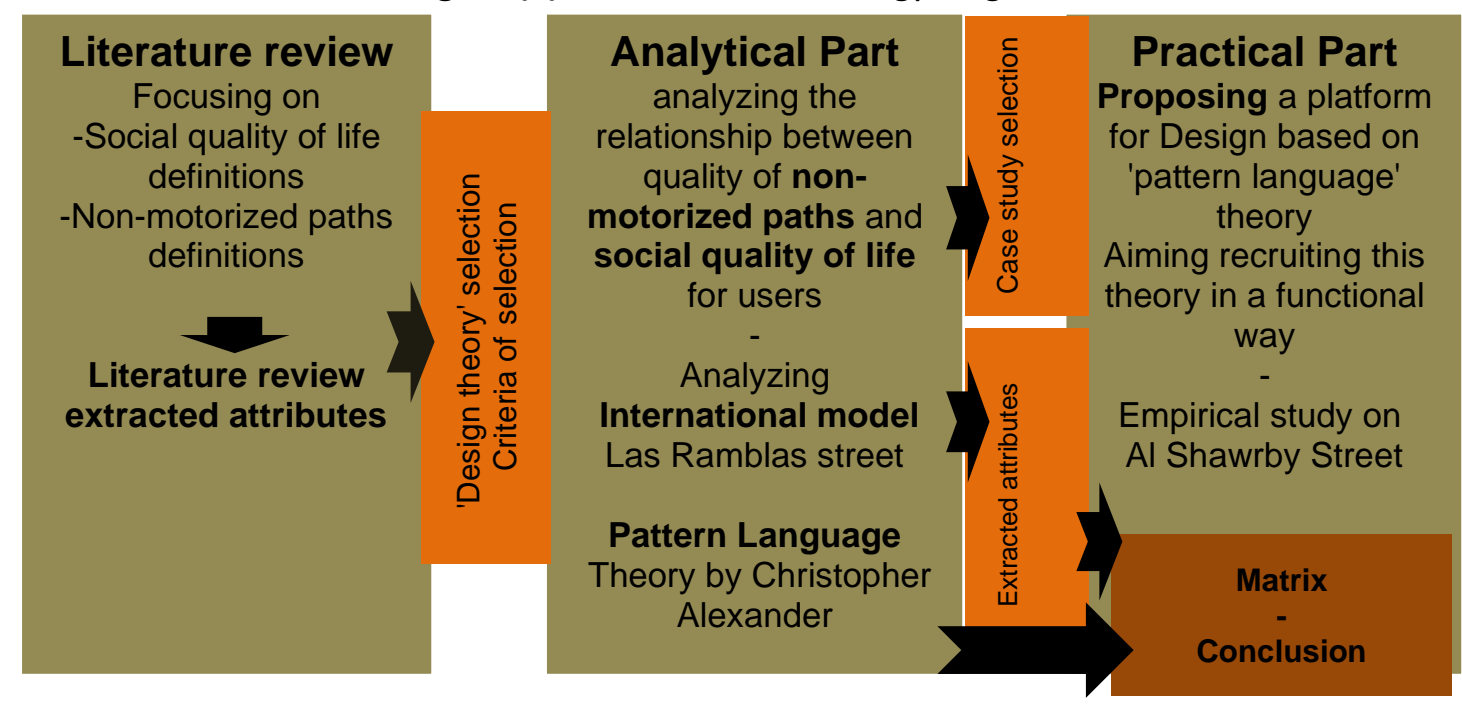

Source: The Author

\section{NON-MOTORIZED PATHS - BACKGROUND AND OVERVIEW}

All over the world, development in most cases is allowed to spread without any plan for public space. Sometimes, designers create public space that is actually private such as behind the walls of gated communities, or inside malls. Streets, in particular, have for a long time ago been a vital part of the public realm, providing a place where merchants can sell their wares, street vendors can occupy a space, children can play, and people can stop to talk. Yet the growing prevalence of the motorized vehicles has squeezed out these uses. However, reclaiming streets as places for people can strengthen cities economically, environmentally, as well as socially (UNHABITAT, 2012). 
For that Pedestrian-priority Commercial Street combines both activities: shopping and walking. People nowadays are moving back to walk-able neighborhoods where they can safely walk and use cycles over vehicular use; moreover, no doubt that shopping at the mall is not just the same as strolling along shopping Pedestrian Street used to be. The mall lacks the interesting mix of people, the social interaction and community activities. (Fadda, et al, 2017)

Moreover, dealing with the streets as social spaces, where people can safely walk, stroll, bike, socialize, and go shopping rather than only experiencing the streets as conduits for vehicular traffic has been recently discussed. It has been known that the concept of streets as public spaces is not new and has already been suggested by many theorists and urban designers since Jane Jacobs's first publications on the significance of streets and sidewalks as the main public places of the city (Fadda, et al, 2017), moreover it is agreeable that pedestrianization would increase sales and retail rent in pedestrian commercial streets (Fadda, et al, 2017).

\section{TOWARDS "SOCIAL" QUALITY OF LIFE}

Neighborhoods and streets are considered the actual sites where social urban qualities such as social interaction, collective activities, and public engagement are practiced by the inhabitants on a daily basis (Shirazi \& Keivani, 2018). Streets are dominant whether motorized or non-motorized, yet Benefits of converting streets to non-motorized paths go through many social streams such as Social Interaction Enhancement, Sense of Security and Safety Increase, Community Livability Enhancement, and Public Spaces Provision (Shirazi \& Keivani, 2018). In addition to this, Social quality of life has been conceptualized around a number of key principles such as social engagement, social inclusion and social mix, social interaction, sense of place, safety and security, and quality of the built environment and dwelling.

Nevertheless planners were interested in improving the quality of life for users through the quality of services such as quality of buildings, public and recreational places, transport and public facilities, and attention to the needs of people with special needs, while social quality of life combines physical environment design with emphasis on the way people live, use the space to function and relate to each other, accordingly offering activities that bring all residents together such as a place for social learning and socialization for children as well as young people, moreover it must meet many functions; economic, social and cultural nevertheless beauty as well as the meaning held in the physical environment must have high priority. However, one of the key goals of social quality of life is to link urban development to social development; promote community organization and participation; increase community safety and prevent unsecured activities; and help strengthen the sense of community belonging, social cohesion, and equitable relationships among genders (Elsemary, 2017).

Comprehensively the concept of quality of life is an integrated concept, encompassing many environmental aspects of urbanization, human and social aspects that reflect people's satisfaction with their lives and communities. Additionally, the requirements and needs of users vary from place to place in the 
same city (Elsemary \& Ismael, 2018), others considered as the basis of the quality of urban life, such as equality, culture, customs and traditions (Carmona, et al, 2010).

However to wrap up what have been said previously, indicators that must be met within the residential cities to achieve quality of life vary between several fields; Urban, Environmental, Social and Economic indicators, some are objective indicators and others are subjective, the Urban indicators could be identified into; Residential Areas including availability of infrastructure as well as planning standards and urban fabric, providing public services, transportation, open green areas as well as achieving aesthetic qualities, for the social indicators; providing safety and security is a must, as well as providing social integration between the communities as a whole, also neighborhoods territories and public realm, in addition to controlling the spaces identified by accessibility and exclusion (Carmona, et al, 2010).

\subsection{Social Quality of Life Extracted Attributes}

From the previous, public spaces are vital ingredients of successful cities and the truth is that even a small investment in quality public space delivers a return to the cities with the foresight to see its value. However, by strengthening the social fabric all over the city, providing economic opportunity, and enhancing the well-being of residents, public space can make limited resources go further and enrich the community and the society as well, even if it is not immediately apparent. Sometimes it is obvious; a shaded park with walking paths and benches; a wellorganized promenade; a boulevard lined with sidewalks, a grand plaza surrounded by buildings; mini plazas as well as nodes for gathering; a gathering place dedicated for children; ramps instead of stairs for the special needs; non-motorized paths only for bikes; shopping streets with pleasant visual image.... etc.

\section{MATERIAL AND METHODS}

\section{DESIGN THEORY SELECTION}

The research selected one of the Design Theories to be the framework for application; some points are set as criteria for choosing this theory:

-A theory based on Design Method/Approach

-A theory that embed many theories

-A theory that is dedicated to solve design problems

-A theory that can be applicable

-A theory that can be tested in a quantitative form

-A theory includes diverse variables

-A theory to be applied in the 2D or 3D

Therefore, the 'Pattern Language' theory by Christopher Alexander had been selected in which it is a set of instructions for reaching correct and valid conclusions.

\section{ANALYTICAL PART}

The analytical part aims at investigating the relationship between the quality of nonmotorized paths and the social quality of life for users in the city by focusing on one of design theories 'pattern language' as an attempt to solve design problems in the 
non-motorized paths, within the help of leading international models deducing the attributes that contribute to measuring and upgrading the quality and efficiency of non-motorized traffic paths, Las Ramblas street in Barcelona-Spain is taken as an analytical case study.

\subsection{Christopher Alexander: A Pattern Language Theory}

It is the second part of a single work by Christopher Alexander had been presented in two halves; volume 1: The Timeless Way of Building; provides a language for building and planning, volume 2: A Pattern Language; provides the theory and instructions for the use of the language. The first book describes the detailed patterns for towns and neighborhoods, houses, gardens and rooms; the other book describes the discipline which makes it possible to use these patterns in creating a building or a town. The essence of the 2 halves is that towns and buildings will not be able to come alive, unless they are made by all people in society, and unless these people share a common pattern language (Alexander, 1977).

It is a theory based on the work of Christopher Alexander and his colleagues in University of California Berkeley, they collect 253 patterns as a whole, as a language, within which they can create an infinite variety of combinations. It is a design relies on certain "languages", which allow the communication of infinite variety of designs within a system and instructions, while the Patterns, the units of this language, are answers to design problems, and they were ordered beginning with the very largest, for regions and towns, then working down through neighborhoods, clusters of buildings, rooms and alcoves, ending finally with details of construction. As a conclusion, no pattern is an isolated entity; each pattern can exist only if it is supported by other patterns (Alexander, 1977).

Supporting these patterns; Paul Alan Johnson argued that many patterns of which rely on behaviorally determinable settings, they are all couched in the phenomenological language of life-events and the descriptive language that elaborate from these concepts, it is the idea of being attached to human activities and hence this is the conventional ideal wisdom of designing (Johnson, 1994).

\section{Alexander illustrates the patterns of this pattern language as:}

1-A problem statement

2-A discussion of the problem with illustration

\section{3-A solution}

The format of presenting the patterns of this pattern language as stated in his book is as follows:

1- A picture, describing the archetypical example of the pattern

2- An introductory paragraph, sets the context for the pattern by explaining how it helps to complete certain other patterns

3-Three diamonds, $\left({ }^{* * *}\right)$ to indicate the beginning of the problem

4- The problem, in bold type headline

5- Long section, describes the empirical background of the pattern, evidence for its validity, range of manifestations in buildings, etc.

6- The solution, in bold type headline 
7- A diagram, the solution in diagram form

8- Three diamonds, $\left({ }^{* * *}\right)$ Pattern main body finished

9- A paragraph, tying the pattern with smaller ones

Moreover, Christopher Alexander admitted that Patterns are interconnected and not isolated, and Problems and solutions can be judged and modified, he and his team also recognized that each pattern may be looked as a hypothesis and each pattern is evolving and can be improved. Moreover, Chris Alexander had categorized the pattern in 3 different types as a result after solving the problem. First one, he gave it the form of ${ }^{* *}$, he meant by this, success in stating a true invariant, and he then summarizes a property common to all possible ways of solving the stated problem, also he means it's not possible to solve the problem properly without use of the pattern in shaping the environment in one way or the other, second probability or result is when he put one diamond only as *, he meant by this; he had made some progress in stating a true invariant, and solution can be improved, and he calls others to seek out variants of the solution, as if he and his team meant that other ranges of the solution are not covered in the written explanations. While the last probability or result, he expressed it by putting no diamonds, and he meant that he hadn't succeeded in defining a true invariant, and there are certainly other ways of solving the problem other than the presented, and he insisted then that the true invariant, as well as the true property behind all possible solutions to this problem remain unfound (Alexander, 1977).

\subsection{International Case Study Selection Criteria}

Various streets could be cases for analysis in this topic, yet the research chose Las Ramblas Street in Barcelona for fulfilling the following criteria:

-socio-cultural as well as commercial street.

-Non-motorized paths included.

-Touristic street .

-Visual image elements are existed; paths, districts, landmarks, edges, nodes.

-Starts and ends with focal landmarks.

-Existence of services targeting upgrading tourism.

\subsubsection{Las Ramblas street - an overview}

Las Ramblas street is the most famous street in Barcelona, as well as one of the most attractive places of the Catalan capital, considered one of the most essential attractions to go in Barcelona, it starts at the epicenter of Barcelona, Place Catalunya (Catalonia Square), then accordingly stretches along many important spots, its dominant importance in providing huge public spaces for laymen to meet and gather in their daily lives rather than the existing inhabitants, the street owes restaurants, cafes, shops, markets and cultural institutions. Las Ramblas marks the limit between Barrio Gothic Quarter and El Raval. Barcelona's cathedral, as well as Place Sant Jaum which houses the main Catalonian Government Building and the City Hall, as shown in the following map, Figure (2). 
Figure (2) Las Ramblas street illustrated by the Author

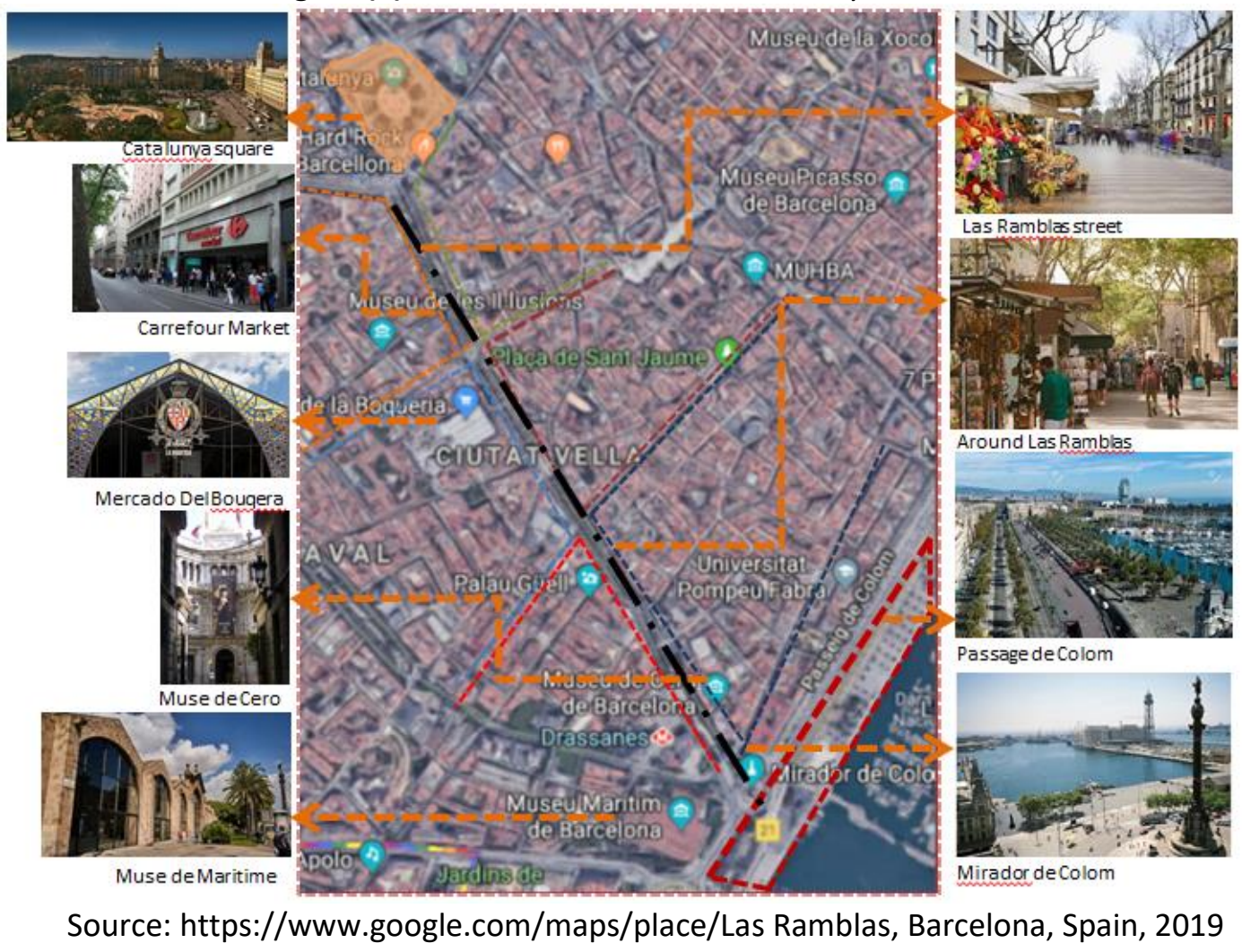

The street starts from plaza Catalonia and ends with the Columbus Memorial in Port Feille, composed of five pedestrians paths from North to South, its creativity because of development of this street wasn't based on planning, it has 40 feet pedestrian path along the center, floor tiled and greenery embedded, booths included in an attractive way, on the two sides located a motorized traffic lane, buildings are maximum 5 floors high which gives a full pleasant visual image, this street used for festivals, carnivals, bazars and daily vivid activities. This massive contribution to the built environment of Barcelona has been planned with an intention to deliver a wellintegrated new public service, designed to be safe, calm, spacious and accessible as shown in Figure (3).

Figure (3) Las Ramblas street showing pedestrians, sheds, buildings and shops
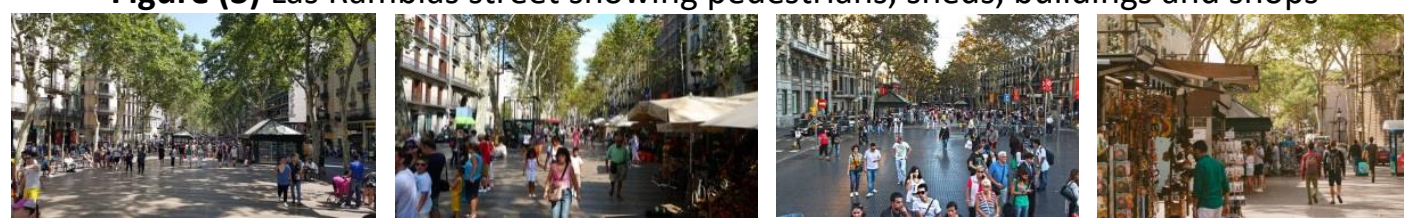

Source: the Author, 2018

\subsection{Attributes Extracted from Analytical Case Study}

Safety and security because pedestrian paths are existing more than motorized traffic lanes, as well as maintenance all over the year, various spaces for dominant events and festivals, focusing on historical characters as well and landmarks in a memorial way such as Columbus memorial, various pleasant parks, valid street furniture such as floor tiles, seats, lighting units, gates, sheds, garbage baskets, stairs, escalators as well as ramps, advertisements display signs, shopping stores and 
restaurants for daily life and it is worth to say that old historical buildings give value to the street just as shown in the following figures, figure (4).

Figure (4) Las Ramblas street

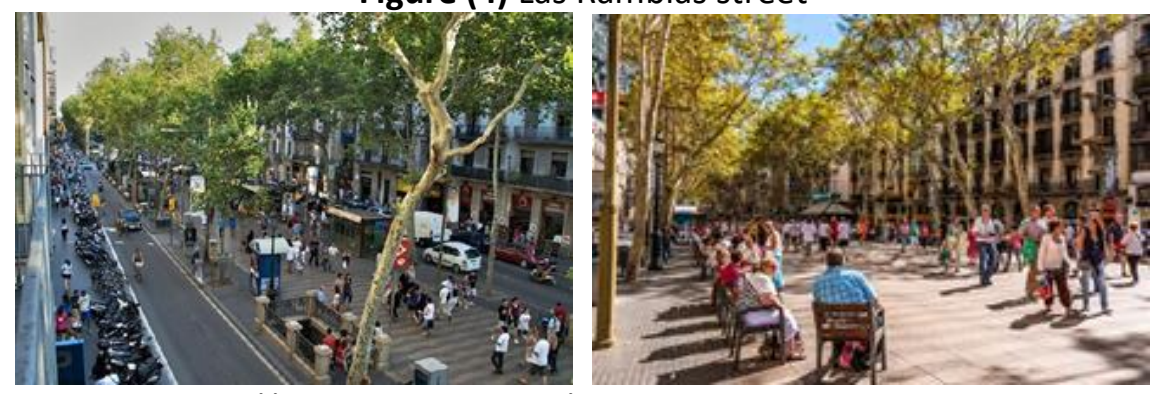

Source: https://www.google.com /Las Ramblas, Barcelona, Spain, 2019

\section{PRACTICAL PART}

Various local Cairien streets could be selected in the practical part, yet the research chose AL Shawarby Street in Down Town for fulfilling the following criteria:

-Old historical street.

-Commercial street.

-Non-motorized path.

-Residential buildings heights are maximum 5 floors.

Al Shawarby Street is a pedestrian one, extended from Qasr El Nil street to Abdel Khaleq Tharwat Street in Bab el Louq, Abdeen District, Cairo Down Town, as shown in the following map, figure (5). Since 100 years, this street known as a commercial one for owing various shops targeting recent fashions, its name derived from $A L$ Shawarby Residential Building designed by the Lebanese Architect Habib Aerout as shown in figure (6). It has been an attraction node to international tourists, local visitors and community surroundings as well, figure (7).

Figure (5) left photo, a part of Down Town map shows Al Shawrby Street in a thin green line, located between Qasr El Nil Street and Abdel Khaleq Tharwat Street, right photo, Al Shawrby street google map

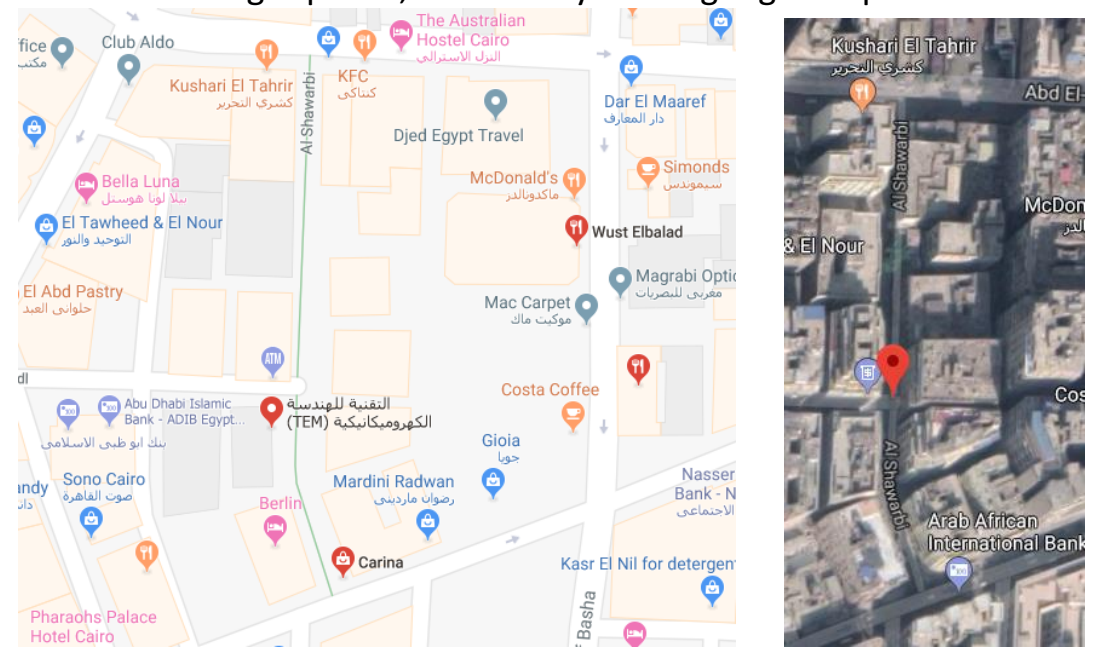

Source: https://www.google.com/maps/place/Al+Shawarbi,+Bab+Al+Louq,+Abdeen,+Cairo+ Governorate, 2019 
Figure (6) Al Shawrby Building

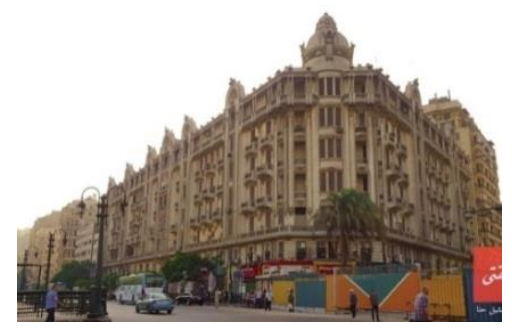

Source: The Author, 2018

Figure (7) Al Shawrby Street
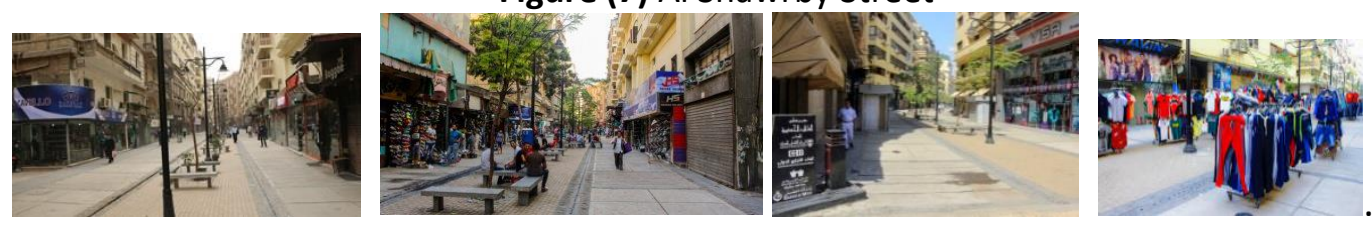

Source: The Author, 2018

Considering Christopher Alexander and his colleagues advice through the different applications in their book, stating that each society should have its own unique \& distinct pattern language, as well as each individual, partly shared by others, however people should be encouraged to make their own pattern language, hoping that each society could be more effective in design, where people should become conscious of their pattern language and work on improving it, accordingly and based on this, the research selected an existed pedestrian path works as a non- motorized traffic path for the past couple of years aiming to let the people improve their unique pattern language in, consequently a questionnaire had been distributed to various volunteers in the street in different times in order to help in applying the pattern language theory, yet first they were asked about what they prefer in the street, what they need, what they miss, second, how do they spend their day in the street, how do they find the shops and furniture in the street, and other questions.

\section{RESEARCH APPROACH}

Methodologically, this research adopts case study approach, a case study was selected for the analytical part and other case study was selected for the empirical part, the research uses the survey approach to explore the aspects that the pedestrians need in their streets, a questionnaire was designed to investigate the pedestrians' points of view, it was addressed to laymen who use Al Shawrby street.

\subsection{Questionnaire Development}

The first part of the questionnaire deals with basic information about the participants, the second part asks about the number of times they visit the street then the third part asks about the lack they are finding in the street facilities in order to be a good public destination.

\subsection{Data Analysis}

The research utilized Microsoft Excel program for organizing the data of the questionnaire then conducting the statistical analysis. Odd data were excluded, and incomplete surveys were ignored. 


\section{RESULTS AND DISCUSSION}

Each place, each culture, is unique. Questions of social norms, climate, and tradition were considered. The goal is to upgrade the vision in such streets. One can wonder how city centers are changing and how this development can be managed looking at the city center of different cities as for making new downtowns of new districts in old cities. The volunteers were aware enough to the idea of developing "places" that are planned for major public destinations, and social cohesion as well as human happiness. Targeting many design features, the list of requirements that were added by volunteers is as following:

-new floor tiles

-a flower market, to be a regular bi-weekly event

-new asphalt surfacing

-a giant chessboard made out of plywood and billiard tables

-cafés and restaurants could be in the form of booths

-night lighting to be distributed along the street

-an installation of new street furniture

-performances, dances, and children's programs such as workshops

-flower gardens planted

-new banners and street signage

-a giant TV screen

-shading devices

-Art and Graffiti

-identified bicycle paths

-enhancing visual image in shops face lifting

The research tried to connect the volunteers' requirements with the pattern language of Christopher Alexander, in a way of tailoring the elements because no pattern is an isolated entity, yet repairing the context around it is a must. The following table demonstrates each requirement with the equivalent to it from Alexander's pattern language list and an illustration to the pattern by a sketch or a photo, and then follows by a full application to the pattern chosen using Christopher Alexander process.

Table (1) The volunteers' requirements regarding upgrading the shopping street and the pattern language equivalent to

\begin{tabular}{|l|l|l|}
\hline \multicolumn{1}{|c|}{$\begin{array}{c}\text { Volunteers' } \\
\text { Requirements }\end{array}$} & $\begin{array}{c}\text { Equivalent from } \\
\text { Christopher Alexander } \\
\text { Pattern Language }\end{array}$ \\
\hline new floor tiles & $\begin{array}{l}\text { 233-floor surface } \\
248 \text { - soft tile and brick }\end{array}$ \\
\hline $\begin{array}{l}\text { flower market, to be a } \\
\text { regular bi-weekly event }\end{array}$ & $\begin{array}{l}46 \text {-market of many } \\
\text { shops }\end{array}$ & \\
\hline
\end{tabular}




\begin{tabular}{|c|c|c|}
\hline new asphalt surfacing & $\begin{array}{l}\text { 233- floor surface } \\
\text { 248- soft tile and brick } \\
\text { 207- good materials }\end{array}$ & \\
\hline $\begin{array}{l}\text { giant chessboard made } \\
\text { out of plywood and } \\
\text { billiard tables }\end{array}$ & $\begin{array}{l}\text { 72- local sports } \\
106-\text { positive outdoor } \\
\text { space } \\
124-\text { activity pockets }\end{array}$ & 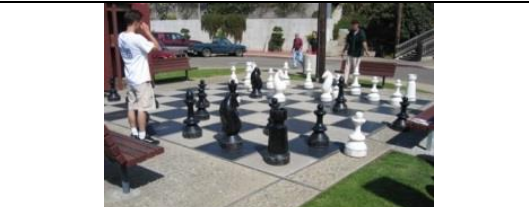 \\
\hline $\begin{array}{l}\text { cafés and restaurants } \\
\text { could be in the form of } \\
\text { booths }\end{array}$ & $\begin{array}{l}\text { 30- activity nodes } \\
88 \text { - street café } \\
93 \text { - food stands } \\
241 \text {-seat spots }\end{array}$ & and \\
\hline Enhancing night lighting & 33- night life & \\
\hline new street furniture & $\begin{array}{l}\text { 176-garden seat } \\
\text { 251- different chairs }\end{array}$ & \\
\hline $\begin{array}{l}\text { performances, dances, } \\
\text { and children's programs } \\
\text { such as workshops }\end{array}$ & $\begin{array}{l}\text { 56- bike paths and racks } \\
63-\text { dancing in the street } \\
73-\quad \text { adventure } \\
\text { playground }\end{array}$ & \\
\hline flower gardens planted & $\begin{array}{l}\text { 171- tree places } \\
245 \text {-raised flowers }\end{array}$ & \\
\hline $\begin{array}{l}\text { new banners and street } \\
\text { signage }\end{array}$ & $\begin{array}{l}\text { 36- degrees of public } \\
\text { ness } \\
100 \text {-pedestrian street }\end{array}$ & \\
\hline shading devices & 119-arcades & \\
\hline Art and Graffiti & $\begin{array}{l}\text { 100- pedestrian street } \\
166 \text { - gallery surround }\end{array}$ & \\
\hline identified bicycle paths & $\begin{array}{l}\text { 31-promenade } \\
56 \text { - bike paths and racks }\end{array}$ & \\
\hline
\end{tabular}




\begin{tabular}{|l|l|}
\hline $\begin{array}{l}\text { enhancing visual image } \\
\text { in shops face lifting }\end{array}$ & $\begin{array}{l}\text { 121-path shape } \\
\text { 122- building fronts } \\
\text { 250-warm colors }\end{array}$
\end{tabular}

Source: The Author

Figure (8) 32 SHOPPING STREET **

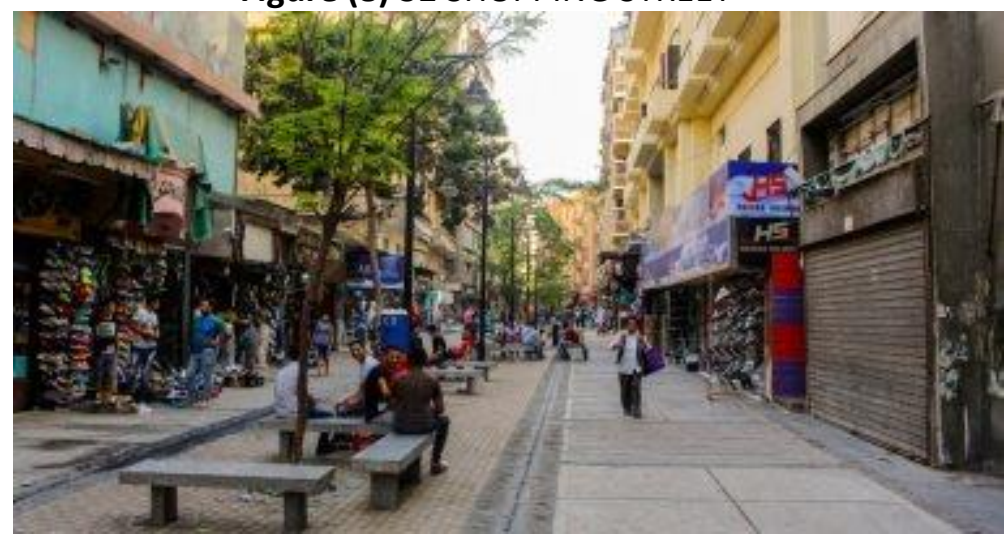

Source: The Author, 2018

This pattern forms essential nodes of life, help to generate activity nodes (30), street café (88), promenade (31), enhance bike paths and racks (56), grow the feeling of night life (33) by enhancing night lighting in a good way, formulate the path shape (121), by providing market of many shops (46), local sports (72) such as chessboard and billiard, activity pockets (124) and positive outdoor space (106), to begin forming vital spots of a community by identifying bike paths and racks (56), degrees of public ness (36) by adventure playground (73), garden seat (176), different chairs (251) as a trial to act as a pedestrian street (100) and a big gallery surround (166).

\section{Pedestrian paths considered as shopping streets are not attractive to the extent that makes pedestrians amuse the whole experience}

Shopping streets are embedded in the urban areas emphasizing subcultures and communities with their boundaries, throughout history there have been places in the city where citizens share their values, and could go to get in touch, shopping streets are examples for these places, yet experiments from the past till now argues that people always seek upgrading in their central shopping spines for the city, their maintenance and proper use require a special pattern accessible, by asking around 400 volunteers, they delivered to the research a lot of experiences they lived, thus derived from several problems, such as lacking cafes and restaurants even in the form of booths, dancing performances and children workshops, moreover it seems that people of all cultures, may have a general need for the kind of human mixing, this had been clear in their demand for a bike path and enhancing a playing area, may include chess board or billiards tables, adding to previous enhancing and emphasizing the visual image in general representing in new floor tiles, garden seats, shading devices, trees and flower markets, new street furniture including lighting units, asphalt surfacing, art and graffiti within the shops ground ribbon face-lifting. 


\section{Encourage shopping in shopping streets rather than shopping malls by enhancing facilities to community surroundings to make them attractive and worth going.}

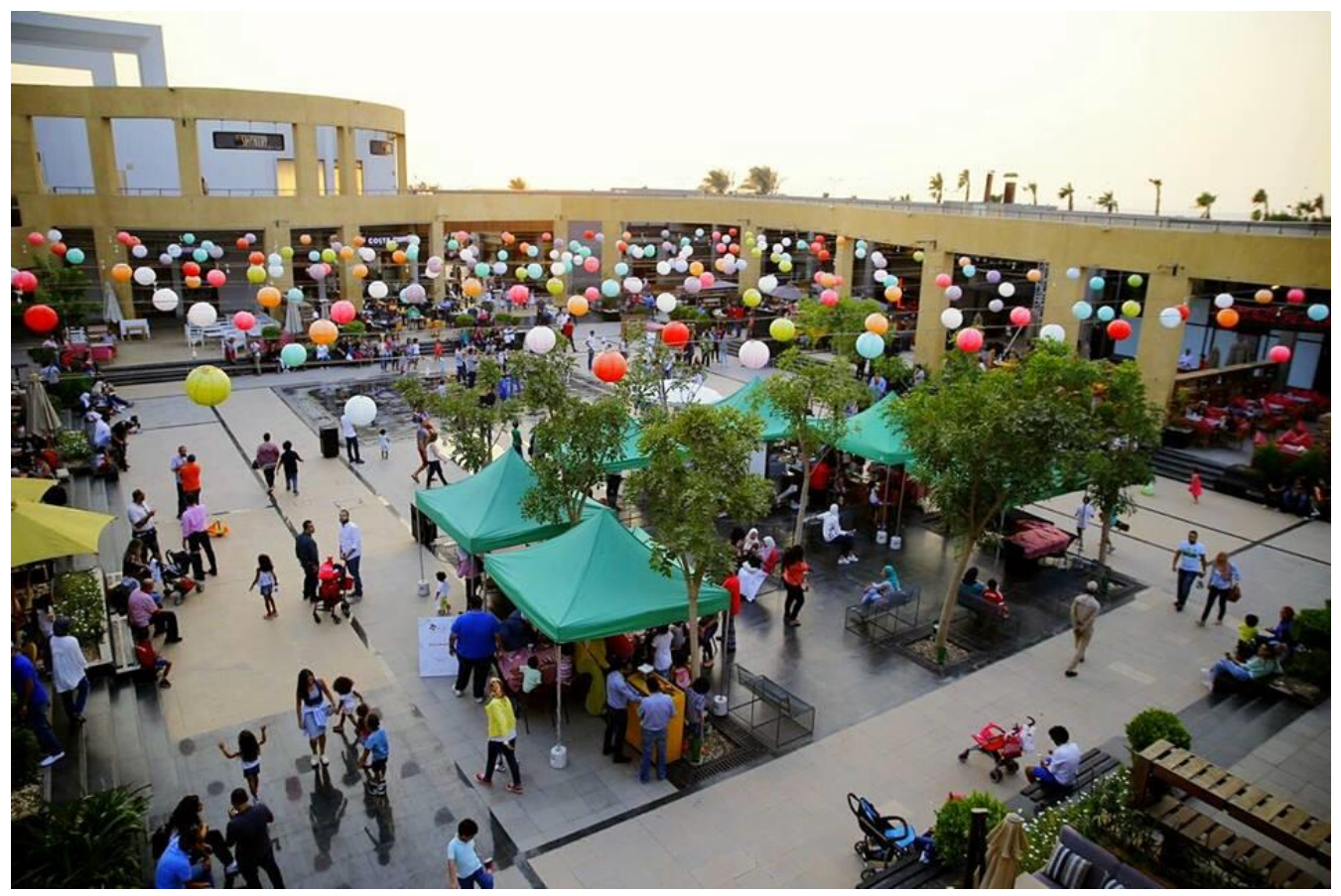

To propose a detailed design encountering many patterns providing a socio-cultural street holding space for entertainment, arts and cultural consumption is a new challenge, nevertheless merging the patterns together, for social interaction enhancement; providing a big gallery surround (166), enhance bike paths and racks (56), activity nodes (30), street café (88), and activity pockets (124) for environmental benefits; establishing tree places (171), raised flowers (245), for economic benefits; Sales \& Retail Rent Increase, and the employment ratio increase when adding market of many shops (46), activity nodes (30), street café (88), and food stands (93).

Wrapping up what have gained from the literature review and what have been extracted in the analytical part and what have been applied in the practical part, for more significance, the researcher merged altogether in the following flowchart, figure (9), some attributes are common such as walking paths, gathering nodes, seats and benches, shopping stores and restaurants. 
Figure (9) A flowchart wrapping up literature review, analytical part and practical part

Social Quality of Life for NonMotorized Paths in Literature Review

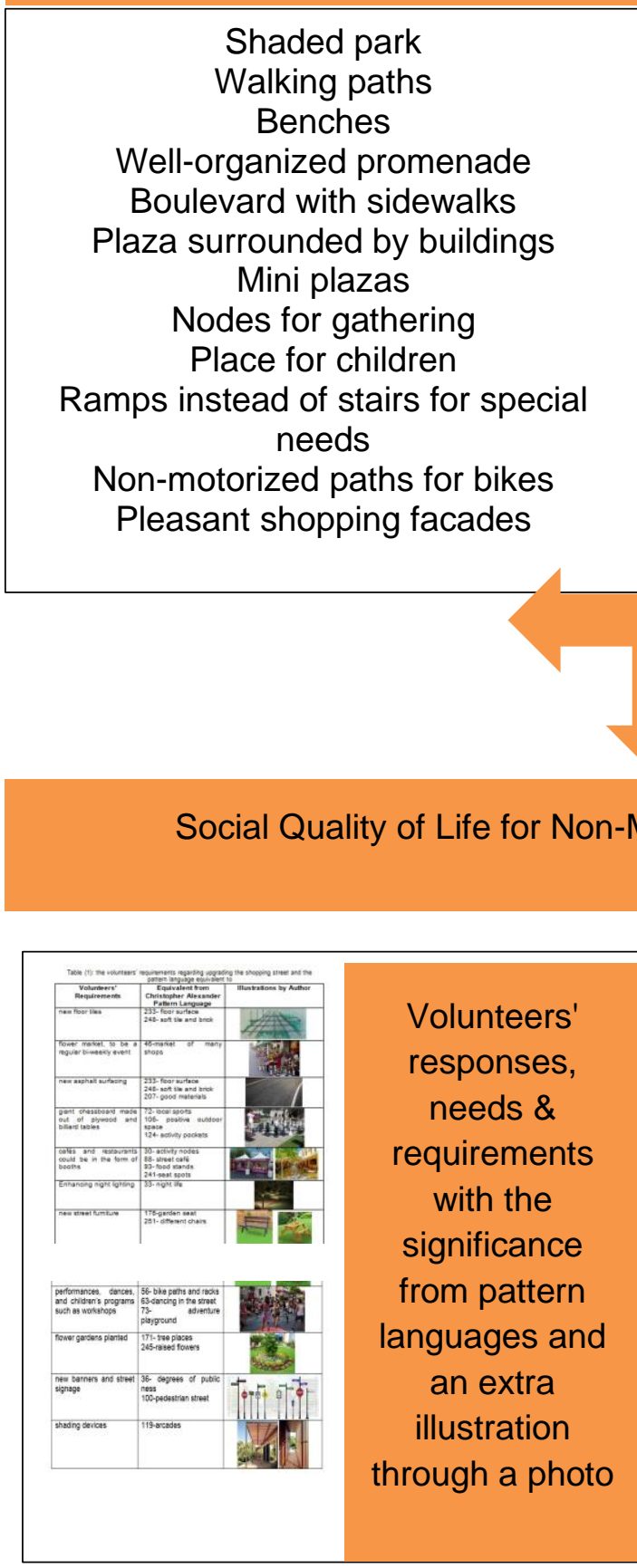

Social Quality of Life for NonMotorized Paths in Analytical Part

\begin{tabular}{|c|}
\hline Safety \& Security \\
Maintenance all over the year \\
Spaces for events \& festivals \\
Landmarks \& Memorials \\
Pleasant Parks \\
Street furniture such as floor tiles, \\
seats, lighting units, gates, sheds \& \\
garbage baskets \\
Stairs-Escalators- Ramps \\
Advertisements Display Signs \\
Shopping Stores \\
Restaurants for daily life \\
Historical Buildings
\end{tabular}

Source: The Author

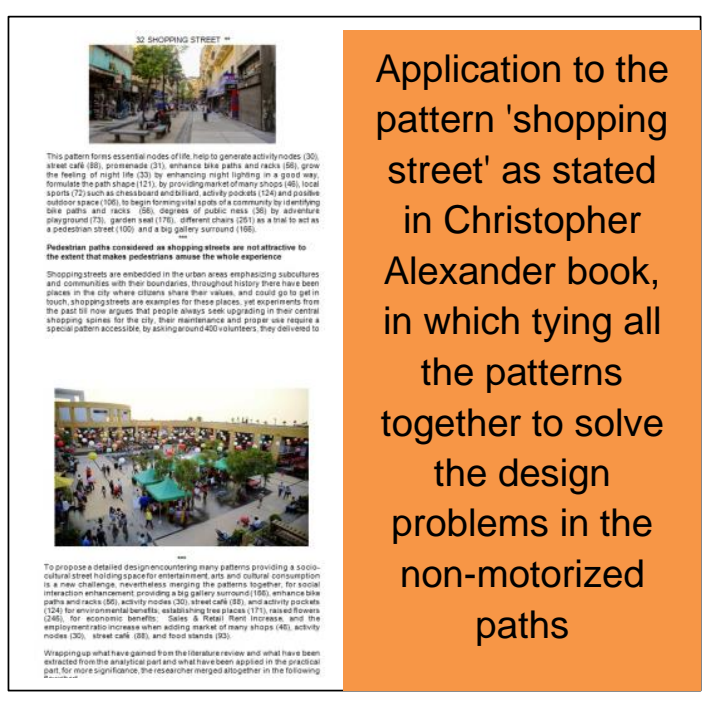

pattern 'shopping

street' as stated in Christopher Alexander book, in which tying all the patterns ogether to solve the design problems in the non-motorized paths

\section{CONCLUSION}

Creative public spaces are today's meeting platform for the urban and architecture on the social, cultural and economic levels. Public spaces are not only matters for planners, designers, and authorities, yet human needs shall be met and fulfilled, For that design serves function and alternatives for usage of public space, The paper deduces new criteria in the Cairene Built Environment sector that can help the urban designer while designing public spaces to meet users' needs based mainly on the 
participation of residents and participants of activities in the selected case study, with the help of thorough application to Christopher Alexander's theory. Moreover, what enables to take Christopher Alexander's theory as an applicable example for what Fish said, and Paul added to; that anything approaching instructions for correct decision-making tends towards method, and is already framed within a theoretical view of architecture, moreover it is a way of leading an already persuaded architect or designer to a resolved outcome (Johnson, 1994).

In summary, this paper shows that residents perceive social quality of life through many factors; socially and culturally as well as aesthetically, they already proposed many solutions to help, such as allowing sustainable maintenance, adding portable markets, providing a public art program bringing some of the world's finest artists into various spots in the street to leave moments of joy and contemplation to the passengers, shaded areas must be taken into consideration, food and beverage booths and other proposals as shown in the previous table, thus the findings of the research succeeded in tailoring the pattern language of Christopher Alexander with the volunteers' proposals and needs as a response to the research hypothesis stated before suggesting that, if Non-Motorized paths considered to be as a catalyst to the social quality of life attributes, as well as activating the Non-Motorized paths by implementing theories of design with special consideration to all aspects of function, environment, and context.... etc. then this would provide the users with their needs and requirements, moreover would support the social quality of life. Architects, and Urban Designers, therefore, need to pay great attention to implementing theories of design in the design process, which may be an important welfare enhancing approach. Moreover, the research proved that quality of non-motorized paths will influence the social quality of life in general.

\section{REFERENCES}

-Alexander, C., et al, (1977). A Pattern Language, Towns- Buildings-Construction. Oxford University Press.

-Carmona, M., et al, (2010). Public Places Urban Spaces, the Dimensions of Urban Design. Second Edition, USA: Routledge.

-Elsemary, Y. (2017). Towards Sustainable Prosperity for Informal Settlements - Al Max, Alexandria and Fes El Bali, Fes as cases study.

-Elsemary, Y. \& Moustafa, N. (2018). The Role of Open Green Spaces in Improving the Quality of life in Residential Cities - An Analytical study of public parks in Greater Cairo.

-Fadda, N., et al, (2017). Reclaiming Streets as Public Spaces for People, Promoting Pedestrianization Schemes in Alshawarbi Commercial Street - Downtown Cairo.

-Johnson, P. A. (1994). The Theory of Architecture: Concepts, Themes and Practices. Van Nostrand Reinhold.

-Shirazi, M. R. \& Keivani, R. (2018). The triad of social sustainability: Defining and Measuring Social Sustainability of Urban Neighborhoods.

-UN- HABITAT \& PPS. (2012). Place making and the Future of Cities. United Nations Federal Credit Union. 